СМЕШАННЫЕ ГРУЗОПЕРЕВОЗКИ

КАК СТРАТЕГИЧЕСКОЕ НАПРАВЛЕНИЕ

В ФУНКЦИОНИРОВАНИИ

\title{
ТРАНСПОРТНО-ЭКСПЕДИЦИОННЫХ КОМПАНИЙ
}

\section{Н.А. Серебрянская}

МГТУ им. Н.Э. Баумана, Москва, Российская Федерация
Senat94@mail.ru

\begin{abstract}
Аннотация
На основе анализа условий работы современных транспортно-экспедиционньх компаний предложено использование моделей смешанных грузоперевозок с иелью расширения географии поставок и интегрирования в систему международных транспортных перевозок
\end{abstract}

\section{Ключевые слова}

Транспортно-экспедиционная компания, смешанные грузоперевозки, мультимодальнье грузоперевозки, транспортная логистика

Поступила в редакцию 18.01.2017

(c) МГТУ им. Н.Э. Баумана, 2017

В современных рыночных условиях транспортно-экспедиционные компании обладают гибкой ценовой политикой, собственными системами продаж, признанием клиентов и долей рынка.

Широкое использование элементов комплекса маркетинга привело к тому, что предприятиям все сложнее конкурировать за счет уникальности тех или иных составляющих. Основным конкурентным преимуществом становится использование инноваций и сокращение затрат, то есть снижение себестоимости услуг, что можно осуществить, применяя на практике модели смешанных грузоперевозок.

Актуальность развития транспортных грузоперевозок обусловлена тем, что ограниченная география поставок продукции, которую обеспечивает транспортно-экспедиционная компания, может быть значительно расширена с минимальными на это затратами. Кроме того, компания получит возможность интегрироваться в международные транспортные перевозки, таким образом, повысив свою привлекательность для клиентов и укрепив конкурентные преимущества.

Анализ научных публикаций по обозначенной проблеме показал, что понятия «смешанные грузоперевозки» и «мультимодальные грузоперевозки» используются авторами как взаимозаменяемые. Чтобы определить различия данных понятий, рассмотрим их значения.

В Конвенции ООН о международных смешанных перевозках грузов представлено следующее определение смешанных перевозок: «...это перевозка грузов, по меньшей мере, двумя разными видами транспорта на основании договора смешанной перевозки из места, где грузы поступают в ведение оператора смешанной перевозки, до обусловленного места доставки» [1]. 
Согласно статье 788 Гражданского кодекса Российской Федерации смешанные грузоперевозки характеризуются как перевозки несколькими видами транспорта, но под ответственностью одного перевозчика по единому транспортному документу и сквозной единой тарифной ставке [2].

Мультимодальная перевозка - это перевозка с использованием нескольких видов транспорта абсолютно в любом сочетании. Зачастую она осуществляется из-за невозможности использовать другой способ перевозки груза, а также с целью снижения затрат или экономии времени. В случае такой перевозки перемещение груза в процессе транспортировки обеспечивается единым документом [3].

Смешанные перевозки груза могут быть раздельными и прямыми (рис. 1). Как видно из рисунка, мультимодальные перевозки являются разновидностью смешанных перевозок, однако под руководством одной компании. Использование раздельных смешанных перевозок и мультимодальных перевозок одной транспортно-экспедиционной компанией позволит повысить вариативность действий, связанных с логистическими операциями по доставке грузов. Отметим, что не всегда необходим единый документ или единый тариф при доставке груза.

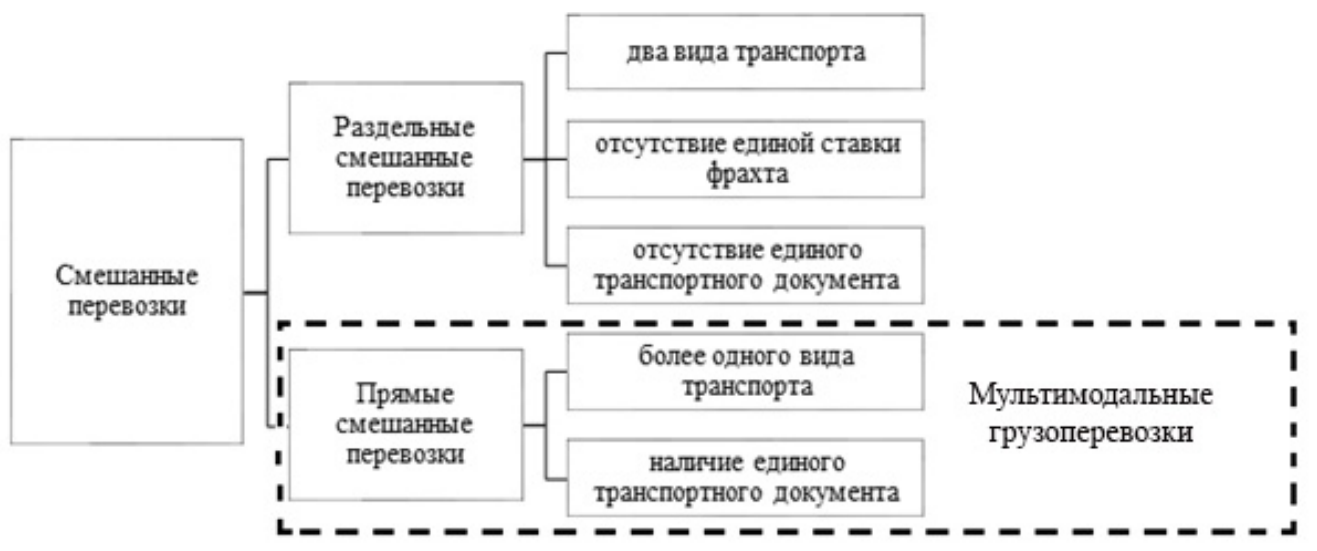

Рис. 1. Смешанные и мультимодальные грузоперевозки

В настоящее время в России отмечен ряд проблем, препятствующих развитию смешанных грузоперевозок. А.Ю. Кривошеев выделил факторы, которые обуславливают низкую эффективность данного вида перевозок (рис. 2). Все обозначенные факторы являются актуальными на рынке.[4]. Таким образом, чтобы сделать более доступными и востребованными смешанные перевозки на территории страны, следует, прежде всего, начать работать над законодательной базой. С целью структурирования данного процесса необходимо разработать единые правила организации таких грузоперевозок и разделения прав и обязанностей между участниками товародвижения.

Несмотря на общую неблагоприятную ситуацию в мировой экономике, в то же время отмечается глобализация производства и капитала как способа повы- 
шения эффективности функционирования путем консолидации усилий разных предприятий.

Мультимодальные перевозки грузов, как и смешанные перевозки, осуществляются на основании договора, экономическая суть которого заключается в доставке груза из пункта отправления в пункт назначения. Представители отечественных транспортно-логистических компаний часто называют его «транспортным договором» [3]. Несмотря на то, что смешанные (комбинированные) перевозки приобретают сегодня особое значение, их правовое регулирование не соответствует потребностям функционирования и развития этих перевозок.

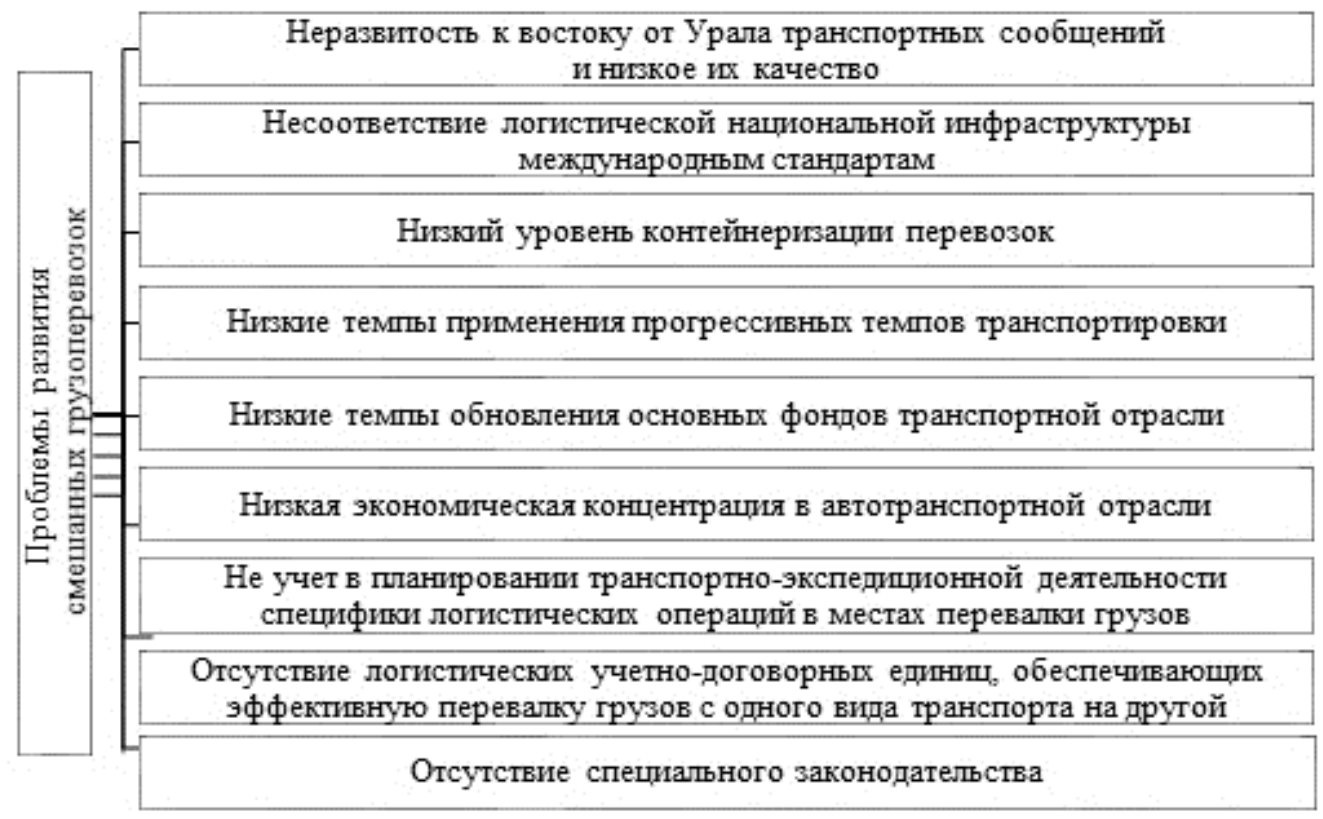

Рис. 2. Причины низкой эффективности смешанных грузоперевозок

В Гражданском кодексе Российской Федерации этому виду сообщения посвящена только 788 статья, устанавливающая, что «взаимоотношения транспортных организаций при перевозке грузов, пассажиров и багажа разными видами транспорта по единому транспортному документу (прямое смешанное сообщение), а также порядок организации этих перевозок определяются соглашениями между организациями соответствующих видов транспорта, заключаемыми в соответствии с законом о прямых смешанных (комбинированных) перевозках». Упомянутый в статье Федеральный закон, на основании которого должны заключаться соглашения о порядке организации перевозки в прямом смешанном сообщении так и не был принят. Таким образом, отсутствие правовой базы, регулирующей прямые смешанные (комбинированные) перевозки, негативно сказывается и на решении теоретических аспектов, и на судебной практике [2]. 
Другая не менее важная проблема развития смешанных грузоперевозок это нерациональная взаимосвязь транспортных и логистических этапов при организации доставки грузов. Поскольку данный процесс не регламентирован на законодательном уровне, он не имеет директив относительно организации этого вида доставки. Это приводит к тому, что организация таких грузоперевозок не имеет целостной концепции в транспортной логистике. Д.Дж. Бауэрсокс и Д.Дж. Клосс видят следующие причины отсутствия целостности в процессе осуществления смешанных грузоперевозок [5]:

- транспортные услуги являются утилитарными услугами, которые имеют прикладной узкопрактический характер. Связь таких услуг с поставками, безусловно, существует. Однако она носит, главным образом, коммуникативный характер, так как транспорт в логистических системах «соединяет» разобщенные места хранения запаса;

- различаются характеристики груза и товара: груз - это товар, принятый к перевозке (транспортировка обеспечивает не все виды потребительской полезности товара); связь между грузом и нужным товаром очевидна только в контексте учета ответственности перевозчиков за сохранность груза;

- транспортировка - эта услуга, повышающая доступность материального ресурса (товара). Достижение этой цели осуществляется путем его перемещения на основе заданных потребителем условий поставки.

Внедрение на предприятии смешанных грузоперевозок как составляющей стратегического развития транспортно-экспедиционной компании позволит достичь следующих конкурентных преимуществ, обозначенных в трудах

В.В. Ткача [6-8]:

- расширить географию деятельности;

- сформировать постоянную клиентскую базу;

- передавать отдельные логистические операции на аутсорсинг;

- диверсифицировать основную деятельность предприятия;

- снизить логистические издержки.

Таким образом, можно сделать вывод, что использование смешанных грузоперевозок транспортно-экспедиционными предприятиями в своей деятельности является важным шагом на пути развития предприятия. Во-первых, это позволит снизить издержки, связанные с доставкой груза в дальние и (или) труднодоступные регионы страны и мира. Во-вторых, предприятия смогут увеличить оборот товаров за счет оказания более широкого спектра услуг своим клиентам, предоставить услуги доставки груза в те регионы, в которые раньше это сделать было сложно или невозможно. В-третьих, использование прямой смешанной (мультимодальной) перевозки, позволит предприятию минимизировать угрозы, связанные с транспортировкой груза, потому как вся поставка будет выполняться на основании одного документа, в котором указаны ответственные стороны за тот или иной участок пути.

В заключение отметим, что в условиях всемирной глобализации мировой экономики, использование транспортно-экспедиционными компаниями сме- 
шанных грузоперевозок является мерой необходимой для получения конкурентного преимущества. В настоящий период времени решение обозначенной проблемы находится в стадии разработки.

\section{Литература}

1. United Nations conference on a convention on international multimodal transport. Volume I, New York. 1981. 21 p.

2. Гражданский кодекс Российской Федерации от 30 ноября 1994 года N 51-ФЗ.

3. Буланова М.Д., Кузьмина М.А., Надирян С.Л. Влияние процесса глобализации мировой экономики на развитие международных смешанных перевозок // Научные труды КубГТУ. № 6. 2015. С. 73-81. URL: http://ntk.kubstu.ru/file/464

4. Кривошеев А.Ю.Логистические проблемы развития смешанных перевозок // Известия СПбГЭУ. 2015. № 3(93). С. 130-134.

5. Бауэрсокс Д.Дж., Клосс Д.Дж. Логистика: интегрированная цепь поставок. М.: ЗАО «Олимп-Бизнес», 2005. 640 с.

6. Ткач В.В. Сервисные приоритеты управления логистическими цепями // Журнал правовых и экономических исследований. 2013. № 3. С. 110-113. URL: http://giefjournal.ru/node/395 7. Ткач B.В. Учет фактора лояльности потребителя и поставщика в планировании поставок в логистических цепях // РИСК. 2012. № 2. С. 77-80.

8. Ткач B.В. Элементы контрактной стратегии управления цепями поставок // Научнотехнические ведомости Санкт-Петербургского государственного политехнического университета. 2012. № 5 (156). С. 147-151.

Серебрянская Наталия Александровна - студентка кафедры «Промышленная логистика», МГТУ им. Н.Э. Баумана, Москва, Российская Федерация.

Научный руководитель - А.М. Иванилова, канд. техн. наук, доцент кафедры «Промышленная логистика», МГТУ им. Н.Э. Баумана, Москва, Российская Федерация. 


\section{INTERMODAL FREIGHT TRANSPORT MODELS AS A STRATEGIC DIRECTION IN THE OPERATION OF FREIGHT FORWARDING COMPANIES}

\section{N.A. Serebryanskaya}

Senat94@mail.ru

Bauman Moscow State Technical University, Moscow, Russian Federation

\begin{tabular}{ll}
\hline Abstract & Keywords \\
Analysing the conditions under which contemporary & Freight forwarding company, in- \\
freight forwarding companies operate, we suggest using & termodal freight transport, multi- \\
intermodal freight transport models for geographic & $\begin{array}{l}\text { modal freight transport, transport } \\
\text { logistics } \\
\text { tional freight transport system }\end{array}$ \\
& C Bauman Moscow State Technical \\
\end{tabular}

\section{References}

[1] United Nations conference on a convention on international multimodal transport. Volume I, New York. 1981. 21 p.

[2] Grazhdanskiy kodeks Rossiyskoy Federatsii ot 30 noyabrya 1994 goda N 51-FZ [Civil code of the Russian Federation from November 30, 1994. N 51-FZ] (in Russ.).

[3] Bulanova M.D., Kuz'mina M.A, Nadiryan S.L. The impact of globalization of the world economy on the development of international multimodal transport. Nauchnye trudy KubGTU [Scientific works of KubSTU], no. 6, 2015, pp. 73-81. URL: http://ntk.kubstu.ru/file/464 (in Russ.).

[4] Krivosheev A.Yu. Logistical problems of multimodal transport. Izvestiya SPbGEU, 2015, no. 3 (93), pp. 130-134 (in Russ.).

[5] Bowersox D.J., Closs D.J. Logistical management: the integrated supply chain process. McGraw-Hill Companies, 1996. 730 p. (Russ. ed.: Logistika: integrirovannaya tsep' postavok. Moscow, ZAO “Olimp-Biznes” Publ., 2005. 640 p.)

[6] Tkach V.V. Logistic priorities of management of economic communications at the enterprises of pulp and paper industry. Zhurnal pravovykh i ekonomicheskikh issledovaniy [Journal of Legal and Economic Studies], 2013, no. 3, pp. 110-113. URL: http://giefjournal.ru/node/395 (in Russ.).

[7] Tkach V.V. Taking into account of the loyalty of the consumer and the provider in planning logistics supply chains. RISK, 2012, no. 2, pp. 77-80 (in Russ.).

[8] Tkach V.V. Contract strategy elements of supply chains management.

Nauchno-tekhnicheskie vedomosti Sankt-Peterburgskogo gosudarstvennogo politekhnicheskogo universiteta [St. Petersburg State Polytechnical University Journal], 2012, no. 5 (156), pp. 147-151 (in Russ.).

Serebryanskaya N.A. - student of Industrial Logistics Department, Bauman Moscow State Technical University, Moscow, Russian Federation.

Scientific advisor - A.M. Ivanilova, Cand. Sc. (Eng.), Professor Assist. of Industrial Logistics Department, Bauman Moscow State Technical University, Moscow, Russian Federation. 